American Journal of Pharmacology and Toxicology 4 (3):46-55, 2009

ISSN 1557-4962

(C) 2008 Science Publications

\title{
Variability in Antihypertensive Drug Therapy and Compliance: Results from a Random Survey in the United Arab Emirates
}

\author{
${ }^{1}$ Syed Azhar Syed Sulaiman, ${ }^{2}$ Muaed Jamal Alomar and ${ }^{2}$ Claire Caroline Strauch \\ ${ }^{1}$ School of Pharmaceutical Sciences, University Sains Malaysia, Penang, Malaysia \\ ${ }^{2}$ Department of Clinical Pharmacy, Faculty of Pharmacy and Health Sciences, \\ Ajman University of Science and Technology Network, Fujairah, \\ P.O. Box 7826 Fujairah, United Arab Emirates
}

\begin{abstract}
Problem statement: Hypertension is one of the most common diseases known as the 'silent killer' because it shows no clinical signs and symptoms. The high prevalence of hypertension in the United Arab Emirates stresses the importance to initiate a nation-wide effort to prevent and control high blood pressure in the population, especially since the prevalence rates are indicative of one of the highest in the world. Approach: This study was designed to investigate the prevalence of hypertension and antihypertensive medications in the United Arab Emirates-Abu Dhabi. A cross-sectional descriptive survey of one hundred sixty hypertensive patient ranging in age from 30 to above 60 years was carried out. A detailed questionnaire was printed out and distributed randomly among hypertensive patients in selected places in Abu Dhabi (pharmacies and hospitals). Results: UAE is a multicultural country with various nationalities living together. $26 \%$ of the patients included in this study were UAE nationals followed by Indians (15\%). The prevalence of hypertension in males was higher than that in females. There was higher prevalence of hypertension in married patients $(80.6 \%)$ as compared with the unmarried group (19.4\%). A correlation exists between the high workload and the prevalence of hypertension. $36.2 \%$ of the individuals with mild obesity were hypertensive, while $26.2 \%$ of them were moderately obese. Obesity is certainly an important factor accounting for hypertension. It is observed that the worst association was obesity and familial history of hypertension, which had a prevalence of $27 \%$, compared with other factors. Conclusion: Physicians, pharmacists and nurses should educate patients to understand their disease process which will help to improve compliance. It was suggested that programs for controlling systemic hypertension should be put in priority and better instructions for the population about the reasons that could make compliance with the antihypertensive treatment difficult, jeopardizing the appropriate control of blood pressure and increasing cardiovascular morbidity and mortality.
\end{abstract}

Key words: UAE, compliance, anihypertensive, adherence, counseling, prevalence

\section{INTRODUCTION}

Prevalence of hypertension: Hypertension is one of the most common diseases. Known as the 'silent killer' because it shows no clinical signs and symptoms, most patients are unaware of their hypertensive state.

It is estimated to be the third leading risk factor associated with death and there are about 600 million affected people worldwide. Hypertension is considered to be the most important risk factor for coronary heart disease, stroke, congestive heart failure, end-stage renal disease and peripheral vascular disease. The National Epidemiological Study of Hypertension in the United Arab Emirates (NESH-UAE) (project was initiated to understand the extent of prevalence of hypertension in the country) shows that in a total of 8,820 UAE citizens surveyed, the overall prevalence of hypertension was found to be $33.1 \% \%^{[1]}$.

Other surveys in the UAE also rate the prevalence of hypertension to be around 36\% (Ministry of Health data $)^{[1]}$.

These preliminary studies are important indications of the high prevalence of hypertension in the United Arab Emirates and stress the importance to initiate a nation-wide effort to prevent and control high blood pressure in the population, especially since the prevalence rates are indicative of one of the highest in the world.

Corresponding Author: Syed Azhar Syed Sulaiman, School of Pharmaceutical Sciences, USM, Penang, Malaysia Tel: 0060164483616 
Studies in Tunisia show that the frequency of hypertension is $29.8 \%$ in the country and is tending to increase with age in both sexes. Similar epidemiological surveys in Saudi Arabia have showed that $22-28 \%$ of the Saudi population is hypertensive ${ }^{[1]}$. A study on school children between the ages of 5 and 13 in Kuwait revealed that $6.8 \%$ of the children were hypertensive ${ }^{[1]}$. In Egypt, studies have shown that the overall prevalence rates of hypertension is $26.3 \%^{[1]}$.

In the US, hypertension not only kills 40,000 Americans every year but it is also considered one of the major factors for the death of 200,000 persons $^{[2]}$.

The risk of developing hypertension increases with age. Men until age 55 are more likely to develop hypertension. After age 55 or after menopause, women lose their hormones that used to help them against blood pressure; consequently the rate of death in woman is higher than men after age $55^{[2,3]}$. The average death in woman due to uncontrolled hypertension is $60 \%$.

According to genes tests, hypertension is slightly higher in blacks than in whites (28.1 vs. $23.2 \%)$. In the age range of 33-44 years old, black women who suffer from hypertension is about $22.9 \%$ while white women $8.5 \%{ }^{[3]}$.

Hypertension affects a large section of the Canadian population. Data from the Canadian Heart Health Survey, which assessed cardiovascular risk factors in a sample of 23,129 randomly selected, non institutionalized Canadian adults aged 18-74 years demonstrated that an estimated 4.1 million Canadians were hypertensive $^{[4]}$. Of the $22 \%$ of Canadians who were hypertensive, $42 \%$ were unaware of having hypertension, $19 \%$ were aware of being hypertensive and were not treated and were not controlled, a further $23 \%$ were treated but were not controlled and only $16 \%$ were treated and controlled ${ }^{[4]}$.

Patient compliance in hypertensive patients: It can be defined as the degree of patient's adherence to medical advice; especially in dietary and lifestyle changes. Following up medical instructions, appointments and taking treatment as prescribed are also considered part of patient compliance. Patient compliance is affected by four main factors; the patient: It is one of the most important factors affecting patient compliance and it includes: Social characteristics such as age and gender. Psychological characteristics such as stress, anxiety or nervousness. Aging: Some patients reject treatment as they consider that this diagnosis is synonymous with the arrival of old age. The disorder: It is difficult to get patient to accept changing their lifestyles or getting treatment and especially most patients have no symptoms. The treatment: The medication's undesirable side effects are a major deterrent to good patient compliance. The more the side effects, the less patient compliance to these medications ${ }^{[5]}$.

Gallup $^{[6]}$ recognized in his study that $11 \%$ of patients treated with an antihypertensive stopped their treatment because of undesirable side effects, $25 \%$ because they thought that their doctor had asked them to stop, $46 \%$ because they thought they had been cured and $6 \%$ for financial reasons ${ }^{[6]}$.

Mallion and Schmitt ${ }^{[5]}$ found in his study that the therapeutic class of the antihypertensive drugs affect the compliance too ${ }^{[5]}$. Second generation angiotensin antagonists have the best level of compliance followed by converting enzyme inhibitors, calcium blockers, beta blockers and diuretics ${ }^{[5]}$.

Bloom ${ }^{[7]}$ recognized data from a large pharmacy database in the United States that when assessing compliance, rates at 1 year, patients treated with angiotensin receptor blockers had greater compliance rates than those treated with other classes of antihypertensive agents. This data was confirmed in a second study assessing compliance rates at 1 year ${ }^{[7]}$. The therapeutic environment: The prescription that the physician has written for a specific patient may affect his compliance. The greater the number of antihypertensive medications or number of tablets taken daily the less the compliance is ${ }^{[5]}$.

Christopher M. Dezii ${ }^{[8]}$ in his retrospective study recognized that patients are more adherent to once daily regimens than multiple daily regimens ${ }^{[8]}$.

"Studies showed that in a population of 105 hypertensive patients, that compliance went from $83.6 \%$ for a single daily dose to $59 \%$ for a three times a day dosage. The legibility of the prescription is also very important since this is generally the only written information given to the patient explaining how they should take the treatment" ${ }^{\prime[5]}$.

Health care professionals (pharmacist or nurses) are also responsible for patient compliance as they have direct contact with the patient ${ }^{[5]}$.

Also the form of medication is very important to patient compliance; some studies show that patients prefer taking one medication (combined form) than taking them separately ${ }^{[9]}$. On the other hand the cost of medications prescribed and its efficacy affect patient compliance too. Noncompliance with medication therapy will impair treatment results.

Causes of patient incompliance: Patient related problems; Misunderstanding the prescribing instructions and leaving the medical team without 
having completed the therapeutic regimen, no faith in the drug's effectiveness, forgetfulness; when a medication is to be used more than once daily, this might cause forgetfulness, disappearance of symptoms; some patients stop taking their medication when symptom relief occur, thinking that they are better and finally, psychological disorders like depression are believed to impair patient compliance. Drug related problems; Adverse drug reactions; Adverse drug reactions may lead patients to stop taking their medication, without knowing that not taking the drug as prescribed will cause more serious complications to $\operatorname{arise}^{[8]}$. Complicated regimens and financial barriers have both shown a negative impact on patient compliance $^{[10]}$.

Improvement of patient compliance: Low-dose combination medication may improve the compliance, because it shows fewer adverse drug reactions. "In a recent study, excellent results have been obtained with the use of small doses of a thiazide diuretic and a bblocker or thiazide diuretic and an angiotensin II receptor blocker" ${ }^{111]}$. The convenience of dosing and development of well-tolerated drugs that are used once daily has resulted in some improvement in patient compliance. Patient counseling is very important in improving compliance. It has been shown that some patients stopped taking their medications believing that the disease had been cured ${ }^{[11]}$.

Treatment of hypertension: A single hypertension medication is not always sufficient to produce the required effect, so physicians prescribe combinations of hypertension medications.

Every medication used lowers blood pressure by about $5-10 \mathrm{mmHg}$. It is very important to set up the correct regimen to ensure that the patient's blood pressure is at the correct level and this is not an easy mission, because many patients already suffer from diabetes, depression or age-related disorders. This means they are already taking medications prescribed to treat those problems.

Because of modern innovations in pharmacology, suitable alternatives to existing medications are used which do not react with hypertensive medications. Depending on the patient's specific needs, physicians prescribe one of the hypertension medications available on the market today.

Hypertension medications are ACE inhibitors, Angiotensin II receptor antagonists, Alpha-blockers, Beta-blockers and Calcium Channel blockers. Practitioners also prescribe diuretics to reduce the water content in the patient's body.
Patients should be monitored regularly by their medical providers, because any change which occurs may be favorable or potentially risky. Physicians can then adjust the hypertension medication to bring the blood pressure back to the required levels.

Medications alone are never enough to address the problem of high blood pressure. They tend to interact with other drugs and the doctor has to restrict intake of such drugs. Patients should make certain lifestyle modifications in order to derive the optimum benefits from antihypertensive. That is achieved by the addition of a certain amount of exercise. A healthy diet must replace an unhealthy one and hypertensive smokers should make a conscious decision to quit because nicotine not only affects the heart and the entire cardiovascular system but also interacts adversely with many hypertension medications ${ }^{[12]}$.

In a study in the United States, it was found that less than $25 \%$ of patients with hypertension have their blood pressure under control, because of noncompliance or inadequate therapy. Treatment failure is related to several factors such as cost, adverse effects of medications or complex drug regimens. There are other lifestyle causes of hypertension such as obesity, volume overload, excess alcohol intake and sleep apnea. These causes should be controlled in order to control blood pressure ${ }^{[13]}$.

Reasons for lack of responsiveness to hypertension therapy: Non adherence to therapy; this is because of one or more of the following reasons: cost of the medication and related care, instructions not clear and/or not given to the patient in writing, failure of the physician to increase or change therapy to achieve blood pressure goals, inadequate or no patient education, lack of involvement of the patient in the treatment plan, side effects of medication, organic brain syndrome (e.g., memory deficit) and/or inconvenient dosing schedule ${ }^{[14]}$.

Drug-related causes: This is because of one or more of the following reasons:

The dose is too low, inappropriate combinations (e.g., two centrally acting adrenergic inhibitors), rapid inactivation (e.g., hydralazine, oral clonidine, captopril, short-acting calcium channel blockers), drug interactions, glucocorticoids, mineralocorticoids, NSAIDs, tyramine and MAO inhibitors, appetite suppressants, phenothiazines, oral contraceptives, sympathomimetics, antidepressants, adrenal steroids, nasal decongestants, cocaine, cyclosporine, erythropoietin, associated conditions, increasing obesity, alcohol intake greater than $1 \mathrm{oz}$ of ethanol per 
day, sedentary lifestyle, sleep apnea, volume overload, inadequate diuretic therapy, excess sodium intake, fluid retention from reduction of blood pressure and/or progressive renal damage $^{[14]}$.

Undesirable side effects of hypertension medications: Commonly, while taking hypertension medications some side effects may occur, most of which diminish with time. In some cases where they persist, physicians may be able to minimize them by lowering the dosage, switching to another drug, or prescribing medication to counteract the side effects. Some side effects which are less severe ones can be managed with lifestyle changes or self-care measures.

Antihypertensive medications are typically used when beginning treatment; they are taken in small doses. The amount of medication taken in a dose is gradually increased until it is at the amount needed to effectively control the high blood pressure. Some common side effects associated with the use of antihypertensive medications include depression, delirium, potassium deficiency and sexual dysfunction.

Beta-blockers lower the rate at which the heart pumps blood, putting the patient at an increased risk of heart failure. Some individuals choose to use these medication because of the relatively low incidence of serious side effects and lower risk of the more common side effects associated with hypertension medications.

Calcium channel blockers are one of the most commonly used hypertension medications. The side effects include headache, dizziness, rapid heart rate and constipation.

ACE inhibitors work as well as calcium channel blockers, but they have the unfortunate side effect of causing an allergic reaction in a small number of individuals that take these types of hypertension medications. The allergic reaction can manifest as a swelling and reddening of tissue and can occur almost anywhere on the body. The most common sites of the allergic reaction are the lips and cheeks. Any reaction to this type of medication should be treated by a medical professional as quickly as possible to reduce the severity of the reaction.

Diuretics have the highest number of side effects associated with them compared to any other medication for hypertension. Typical side effects of diuretics include fever, sore throat, fatigue, muscle cramping and dizziness. Some individuals may experience skin rashes, constant perspiration, loss of appetite, or abnormal heart beat.

These hypertension medications are some of the best available to treat hypertension. For the majority of the individuals taking these medications, the benefits of the drugs far outweigh the risks. Serious side effects occur rarely and many of them can be effectively treated with medical assistance. Often, patients may be on more than one of the common hypertension medications. This makes it imperative that the patient is aware of the potential side effects of the medications so they will be able to tell which one may be affecting them ${ }^{[15]}$.

\section{MATERIALS AND METHODS}

Objective: To evaluate patient adherence and compliance for antihypertensive medications in the UAE.

\section{Methodology:}

Type of study: Descriptive cross sectional survey using questionnaire as a research tool.

Sampling technique: Simple random sampling technique. 160 hypertensive patients were selected randomly from Abu Dhabi in the UAE.

Place of the study: The study was done in the United Arab Emirates, in Abu Dhabi. 160 questionnaires were printed out and distributed in randomly selected places in Abu Dhabi pharmacies and hospitals; the questionnaire was distributed and collected in 1 month.

Some of the questions were answered directly by patients and others by oral interview. After data collection, SPSS v16 were used for analysis in which each question was considered as an independent variable Questionnaire structure: the questionnaire was designed to study the relationship between the following factors and hypertension as a disease and antihypertensive medications:

Nationality: According to the genes tests, hypertension is a little bit higher in blacks than in whites ( 28.1 vs. $23.2 \%$ ). In the $33-44$ age range, black woman who suffer from hypertension about $22.9 \%$ while white woman $8.5 \% \%^{[16]}$.

In another study it has been proven that hypertension is more prevalent in African American and Hispanic women older than 60 years and in white women older than $70^{[17]}$.

Gender: Men until age 55 are more likely to develop hypertension. After age 55 or after menopause, women lose their hormones that used to help them against blood pressure. The average number of deaths among uncontrolled hypertensive, post-menopausal women is $60 \% \%^{[18]}$ 
Marital status: Patients were single, married, widow or divorced. Married women are in general healthier than unmarried woman. In a study in Brazil, The prevalence of systemic hypertension is higher in the unmarried group (divorced/separated and widows) as compared with that of the married one ${ }^{[19]}$.

Oral contraceptive use increases the risk of hypertension, as does the use of hormone replacement therapy among normotensives ${ }^{[18]}$. Hypertension during pregnancy is a common condition and deserves special consideration. Hypertensive disorders are the second leading cause of maternal death and can be harmful to both fetus and the pregnant mother ${ }^{[20]}$.

Age: Arteries absorbs the force of heart contraction, but with time they lose their elasticity, leading to an increase in blood pressure. Blood pressure increases from about $80 / 45$ in infants, to about $120 / 80$ at age 30 , to about $140 / 85$ at age 40 and over. Blood pressure is affected by a wide range of factors and varies between individuals and in the same individual at different times $^{[21]}$.

Job: The relationship between job constraints and hypertension was observed in women more than in men. Some studies emphasize the need of addressing more sex-specific concepts of work related stress and of understanding the direct and indirect mechanisms linking psychosocial factors and hypertension in both sexes $^{[22]}$.

Number of children: this factor was added to test the effect of children on the development of hypertension among their parents.

Smoking: Long-term smokers are highly prone to developing hypertension, because of the effect of nicotine. Hypertensive individuals who smoke have an increased risk of developing malignant hypertension five times greater than non-smokers, Smoking also reduces the effectiveness of certain antihypertensive $\operatorname{drugs}^{[23]}$.

Obesity: Obesity increases the risk of developing disease. According to some estimates compiled by the National Institute of Diabetes and Digestive and Kidney Diseases, almost $70 \%$ of heart disease cases in the United States are linked to excess body fat and obese people are more than twice as likely to develop high blood pressure ${ }^{[24,25]}$.

Obesity and hypertension are closely associated and the degree of obesity is positively correlated with the incidence of hypertension. Obese hypertensive patients may lower their blood pressure by losing weight regardless of a change in salt consumption. Also obesity is also associated with the increased activity of the sympathetic nervous system all of these actions can be reversed by weight loss ${ }^{[2,25]}$.

Eating habits: Eating too many salty foods may contribute to high blood pressure because of fluid retention, which requires more pressure from the heart and kidney to work harder.

Hypertensive patients should consume less than $1500 \mathrm{mg}$ of sodium a day to reduce the amount of stress on the heart. A diet low in salt helps medications work more effectively ${ }^{[26]}$. Fatty, junk-food meals could make heart works harder. People who eat a fatty, junk-food breakfast were more prone to suffer the negative effects of stress than those who eat a healthy, low-fat breakfast" ${ }^{[27]}$.

Are you using prescription medications to control your blood pressure, What was your blood pressure range the last time you checked (choose the range that is closest overall), Have either of your parents, or have any of your siblings had high blood pressure.

Scientists suspect that genetic factors may play a role in this form of high blood pressure. People with family members who have hypertension are more likely to develop it than those whose relatives are not hypertensive ${ }^{[28]}$.

How long have you had high blood pressure, Past medical history and what are the medications used, What do you take for blood pressure, dose and frequency, What did you feel after using these medications.

Life style: A moderate amount of regular exercise has several benefits. It improves overall physical conditions, helps with weight loss by burning extra calories, reduces blood cholesterol and may have a more direct effect on lowering your blood pressure ${ }^{[29]}$.

\section{RESULTS}

The UAE is a multicultural country with various nationalities living together; $26 \%$ of the patients included in this study were UAE nationals followed by Indians (15\%), Syrians (10.6\%), Jordanians (6.2\%), Lebanese (5.6\%), Pakistanis (5\%), Omanis (4.4\%), Iraqis (3.1\%), Yemenis (2.5\%), Egyptians (3.1\%), British $(1.2 \%)$ and other nationalities. $67.5 \%$ of the participants were female and $32.5 \%$ were male. Most participants were married $(80.6 \%)$ with some single, widowed and divorced patients (Table 5). The age was distributed between 30 and 80 years old. Participants occupations were as follows; office workers (33.8\%), 
Table 1: Last BP range distribution

\begin{tabular}{llr}
\hline Last BP range & Frequency & Percent \\
\hline $120-139 / 80-89$ & 79 & 49.4 \\
$140-159 / 90-99$ & 49 & 30.6 \\
$160+/ 100+$ & 16 & 10.0 \\
Not Sure & 16 & 10.0 \\
\hline
\end{tabular}

Table 2: Obesity distribution

\begin{tabular}{llc}
\hline Obesity & Frequency & Percent \\
\hline Not Obese & 53 & 33.1 \\
Mildly Obese & 58 & 36.2 \\
Moderately Obese & 42 & 26.2 \\
Morbidly Obese & 7 & 4.4 \\
\hline
\end{tabular}

Table 3: The distribution of the most common adverse drug reactions versus nationality

\begin{tabular}{|c|c|c|c|c|c|c|c|c|c|c|c|c|}
\hline $\mathrm{ADR}$ & $\begin{array}{l}\text { UAE } \\
43\end{array}$ & $\begin{array}{l}\text { I } \\
24\end{array}$ & $\begin{array}{l}\mathrm{S} \\
17\end{array}$ & $\begin{array}{ll}\mathrm{P} & \mathrm{J} \\
8 & 10\end{array}$ & $\begin{array}{l}\mathrm{C} \\
1\end{array}$ & $\begin{array}{l}\text { USA } \\
2\end{array}$ & $\begin{array}{l}\text { IR } \\
5\end{array}$ & $\begin{array}{l}\mathrm{Y} \\
4\end{array}$ & $\begin{array}{l}\mathrm{PL} \\
5\end{array}$ & $\begin{array}{l}\mathrm{O} \\
7\end{array}$ & $\begin{array}{l}\text { A } \\
3\end{array}$ & $\begin{array}{ll}\mathrm{L} & \mathrm{G} \\
9 & 1\end{array}$ \\
\hline Painful breast & 1 & & & & & & & & & & & \\
\hline Tiredness & 7 & 2 & & 2 & 1 & 1 & & & & & & \\
\hline Cough & 3 & 1 & & 1 & 1 & 1 & & & & & & \\
\hline Headache & & 1 & & 2 & & & & 2 & & & & \\
\hline Ankle edema & 1 & & 1 & 1 & & & & & 1 & & & \\
\hline Stomach upset & 2 & 4 & 1 & 1 & 1 & & & & & 1 & & \\
\hline Constipation & & 1 & & & & & & & & & & \\
\hline Sexual dysfunction & 1 & & & 1 & & & & & & & & \\
\hline Thirst & 4 & & & & & & & & & & 1 & \\
\hline Lightheadedness & 2 & & & & & & & & & & & \\
\hline Dizziness & 3 & 2 & & & & & & 1 & 1 & 1 & 1 & \\
\hline Congestion & & & & 1 & & & & & & & & \\
\hline Blurred vision & & & & 1 & & & & & & & & \\
\hline Sneezing & & 1 & & & & & & & & & & \\
\hline Dry mouth & 1 & 1 & & & & & & & & & & \\
\hline Drowsiness & & 1 & & & & & & 1 & & & & \\
\hline Fatigue & 1 & 1 & 1 & & & & & & 1 & 2 & 1 & 1 \\
\hline
\end{tabular}

ADR: Adverse Drug Reaction; UAE: United Arab Emirates; I: Indian; S: Syrian; P: Pakistan; C: Canada; USA: United States of America; IR: Iraqi; Y: Yemen; PL: Philippine; O: Oman; A: Algeria; L: Lebanese; G: German. The number under each abbreviation reflects the total number of patients belong to the specific nationality. The first row shows the total number of participants for each different nationality

housewives (25.6\%), physical workers like builders $(21.9 \%)$, retired $(13.8 \%)$ and drivers $(5 \%) .20 \%$ of the participants have 3 children, $11.9 \%$ have 2 children, $10.6 \%$ have 4 children, $7.5 \%$ have no children and one participant had 15 children. (Table 3 and 4) $65.6 \%$ of the participants were non smokers, $23.8 \%$ were smokers and $10.6 \%$ were ex-smokers (Table 6). Blood pressure readings among participants is illustrated in Table 1 and obesity distribution is shown in Table 2 . $53.1 \%$ claim to eat spicy food frequently, $47.5 \%$ eat salty food, $41.9 \%$ eat junk food, $39.4 \%$ eat fatty food. $44.4 \%$ claim that they inherited their hypertension from their parents. When asked how long they had known they were hypertensive, $24.4 \%$ said less than one year, $42.5 \%$ said $1-5$ years, $28.1 \%$ more than five years and the rest are not sure when they had discovered they were hypertensive.
Table 4: The distribution of the most common adverse drug reactions versus gender

\begin{tabular}{lll}
\hline ADR & Male (108) & Female (52) \\
\hline Muscle ache & 2 & 0 \\
Painful breast & 1 & 0 \\
Tiredness & 9 & 5 \\
Cough & 5 & 2 \\
Headache & 5 & 2 \\
Ankle edema & 3 & 1 \\
Stomach upset & 8 & 2 \\
Constipation & 1 & 0 \\
Sexual dysfunction & 2 & 0 \\
Thirst & 5 & 0 \\
Lightheadedness & 0 & 2 \\
Dizziness & 6 & 3 \\
Congestion & 1 & 0 \\
Blurred vision & 1 & 0 \\
Sneezing & 1 & 0 \\
Dry mouth & 2 & 0 \\
Drowsiness & 1 & 1 \\
Fatigue & 5 & 3 \\
Frequent urination & 3 & 0 \\
Weakness & 8 & 2 \\
Sore throat & 1 & 0 \\
\hline
\end{tabular}

Table 5: The distribution of the most common adverse drug reactions versus marital status

\begin{tabular}{lllll}
\hline ADR & $\begin{array}{l}\text { Single } \\
(12)\end{array}$ & $\begin{array}{l}\text { Married } \\
(129)\end{array}$ & $\begin{array}{l}\text { Widow } \\
(15)\end{array}$ & $\begin{array}{l}\text { Divorced } \\
(4)\end{array}$ \\
\hline Muscle ache & 0 & 1 & 1 & 0 \\
Painful breast & 0 & 0 & 1 & 0 \\
Tiredness & 0 & 9 & 5 & 0 \\
Cough & 2 & 5 & 0 & 0 \\
Headache & 1 & 4 & 2 & 0 \\
Ankle edema & 0 & 3 & 1 & 0 \\
Stomach upset & 1 & 8 & 1 & 0 \\
Constipation & 1 & 0 & 0 & 0 \\
Sexual dysfunction & 0 & 2 & 0 & 0 \\
Thirst & 0 & 5 & 0 & 0 \\
Lightheadedness & 0 & 1 & 1 & 0 \\
Dizziness & 0 & 6 & 3 & 0 \\
Congestion & 0 & 1 & 0 & 0 \\
Blurred vision & 0 & 1 & 0 & 0 \\
Sneezing & 0 & 1 & 0 & 0 \\
Dry mouth & 0 & 2 & 0 & 0 \\
Drowsiness & 0 & 1 & 1 & 0 \\
Fatigue & 1 & 7 & 0 & 0 \\
Frequent urination & 0 & 2 & 1 & 0 \\
Weakness & 1 & 7 & 2 & 0 \\
Sore throat & & & & \\
\hline
\end{tabular}

Most smokers were Indians (6/160) followed by UAE nationals (5/160) and Philippines (3/160). For moderately obese patients, UAE nationals have the highest percentage (9/160 followed by Indians (8/160). UAE nationals also have the highest percentage in eating spicy food (23/160) followed by Indians (14/160) and Syrians (11/160). UAE nationals occupy the highest percentage in eating salty, junk and fatty food. For the distribution of adverse drug reactions over nationality Table 3 . 
Sixty two patients $(38.8 \%)$ had diabetes in addition to hypertension, 39 patients $(24.4 \%)$ suffer from hypercholesterolemia and 27 (16.9\%) suffer from GIT problems. While congestive heart failure is less prevalent $(8.1 \%), 24$ patients $(15 \%)$ suffer from diabetes mellitus and hypercholesterolemia in addition to hypertension. Only two patients (1.25\%) suffer from hypertension, hypercholesterolemia, congestive heart failure and diabetes mellitus. Two patients (1.25\%) are morbidly obese; eat spicy food, salty food and junk food. There is no difference in the incidence of adverse drug reaction between female and male genders. The percentage of smoking among males $(8.75 \%)$ is much higher than females $(1.88 \%)$. No difference in blood pressure readings between female and male genders where seen in the study.

\section{DISCUSSION}

The most common adverse drug reaction of Perindopril is headache which reaches up to $23 \%$. Among 1,012 patients in US trials, the overall frequency of reported adverse events of perindopril was cough $(0.3 \%)$, dizziness $(8.2 \%)$. Other commonly reported complaints $(1 \%$ or greater), regardless of causality, include: Headache $(23.8 \%)$, upper respiratory infection $(8.6 \%)$, asthenia $(7.9 \%)$, rhinitis $(4.8 \%)$, low extremity pain $(4.7 \%)$, diarrhea $(4.3 \%)$, edema $(3.9 \%)$, pharyngitis $(3.3 \%)$, urinary tract infection $(2.8 \%)$, abdominal pain $(2.7 \%)$, sleep disorder $(2.5 \%)$, chest pain $(2.4 \%)$, injury, paresthesia, nausea, rash (each $2.3 \%$ ), seasonal allergy, depression (each 2.0\%), abnormal ECG (1.8\%), ALT increase (1.7\%), tinnitus, vomiting (each 1.5\%), neck pain, male sexual dysfunction (each 1.4\%), triglyceride increase, somnolence (each 1.3\%), joint pain, nervousness, myalgia, menstrual disorder (each 1.1\%), flatulence and arthritis (each $1.0 \%)^{[30]}$.

The most common adverse drug reaction of Amlodipine is edema up to $14.6 \%$, in this study the most common adverse drug reaction of Amlodipine is tiredness (19.2\%).

Amlodipine besylate has been evaluated for safety in more than 11,000 patients in U.S. and foreign clinical trials. Table 7 shows the adverse reactions more than $(1 \%)^{[31]}$.

The most common adverse drug reaction of Carvidilol is dizziness up to $32.4 \%$, in this study the most common adverse drug reaction of Carvidilol is weakness $(33.3 \%)$.

Carvedilol has been evaluated for safety in hypertension in more than 2,193 patients in US clinical trials (Table 8 ). Approximately $36 \%$ of the total treated population received carvedilol for at least 6 months ${ }^{[32]}$.
Table 7: Percent of ADR of amlodipine

\begin{tabular}{ll}
\hline ADR & Amlodipine $(\mathrm{N}=1730)$ \\
\hline Headache & 7.3 \\
Fatigue & 4.5 \\
Nausea & 2.9 \\
Abdominal pain & 1.6 \\
Somnolence & 1.4 \\
\hline
\end{tabular}

Table 8: Percent of ADR of Carvedilol

\begin{tabular}{ll}
\hline ADR & Carvedilol $(\mathrm{n}=1,142)$ \\
\hline Bradycardia & 2 \\
Postural hypotension & 2 \\
Peripheral edema & 1 \\
Dizziness & 6 \\
Insomnia & 2 \\
Diarrhea & 2 \\
Thrombocytopenia & 1 \\
Hypertriglyceridemia & 1 \\
\hline
\end{tabular}

Table 9: Percent of ADR of Atenolol

\begin{tabular}{ll}
\hline ADR & Atenolol $(\mathrm{n}=164)$ \\
\hline Bradycardia & 3 \\
Postural Hypotension & 2 \\
Dizziness & 4 \\
Vertigo & 2 \\
Light headedness & 1 \\
Fatigue & 3 \\
Lethargy & 1 \\
Drowsiness, dyspnea, tiredness and depression & 0.6 \\
Diarrhea & 2 \\
Nausea & 4 \\
\hline
\end{tabular}

The most common adverse drug reaction of Fosinopril is dizziness up to $11 \%$, in this study it is $50 \%$. In a clinical trial on 668 Fosinopril sodiumtreated patients, with usual duration of therapy which was two or three months, Discontinuations due to any clinical or laboratory adverse event were $4.1 \%$. The most common side effects reported were cough $(2.2 \%)$, dizziness $(1.6 \%)$, nausea/vomiting $(1.2 \%)^{[33]}$.

Most common adverse drug reaction of Atenolol is dizziness up to $13 \%$, but in this study the most common adverse drug reaction of Atenolol is weakness (33.3\%).

The estimated frequency of atenolol's side effect in Table 9 was derived from controlled studies in hypertensive patients in which adverse reactions were volunteered by the patients (US studies) ${ }^{[34]}$.

The most common adverse drug reaction of Valsartan is dizziness up to $9 \%$, but in this study the most common adverse drug reaction of Valsartan is fatigue $(28.6 \%)$.

Valsartan has been evaluated for safety in more than 4,000 patients, including over 400 treated for over 6 months and more than 160 for over 1 year. Adverse reactions have generally been mild and transient in nature; the most common reasons for discontinuation of therapy with Diovan were headache and dizziness. 
Table 10: Percent of ADR of Torsemide

\begin{tabular}{ll}
\hline ADR & Torsemide $(\mathrm{N}=564)$ \\
\hline Headache & 7.3 \\
Excessive Urination & 6.7 \\
Dizziness & 3.2 \\
Rhinitis & 2.8 \\
Asthenia, diarrhea & 2.0 \\
ECG Abnormality & 2.0 \\
Cough increase & 2.0 \\
Constipation & 1.8 \\
Nausea, arthralgia & 1.8 \\
Dyspepsia, myalgia & 1.6 \\
Sore Throat & 1.6 \\
Chest Pain & 1.2 \\
Insomnia & 1.2 \\
Edema & 1.1 \\
Nervousness & 1.1 \\
\hline
\end{tabular}

Headache, dizziness, upper respiratory infection, cough, diarrhea, rhinitis, sinusitis, nausea, pharyngitis, edema and arthralgia occurred at a more than $1 \%$ rate $^{[35]}$.

The most common adverse drug reactions for Torsemide in this study were cough and fatigue $(33.3 \%)$.

Torsemide had been evaluated for safety in approximately 4000 subjects: over 800 of these subjects received Torsemide for at least 6 months and over 380 were treated for more than 1 year. The reported side effects of Torsemide were generally transient and the side effects are shown in Table $10^{[36]}$.

\section{CONCLUSION}

The prevalence of hypertension in males was higher than that in females. This may result from the fact that, in this society, males are less concerned with preventive measures of chronic diseases, such as being physically active and eating healthy food.

There was higher prevalence of hypertension in married patients $(80.6 \%)$ as compared with the unmarried group (19.4\%). Whereas in another study in Brazil, it was proven that the unmarried group have higher incidence of hypertension ${ }^{[19]}$.

It was found that there was no significant linear relationship between the number of children a patient had and hypertension.

It's known that smoking is a common risk factor of hypertension and this has been proven in several studies $^{[23]}$. But it is observed in this study that the prevalence of hypertension was higher among nonsmokers $(65.6 \%)$, which may be due to the place of the study and the variations in nationalities in Abu-Dhabi.

It is reconfirmed that diabetes and hyperlipidemia are of the major diseases associated with hypertension. A correlation exists between the high workload and the prevalence of hypertension. It could be assumed that the individual who works more has less or no time for applying measures for changing lifestyles. By that it's higher in patients have physical $(21.9 \%)$ and office work $(33.8 \%)$ than retired $(13.8 \%)$.

In this study, $36.2 \%$ of the individuals with mild obesity (body mass index 25-30 $\mathrm{kg} \mathrm{m}^{-2}$ ) were hypertensive, while $26.2 \%$ of them were moderately obese. Obesity is certainly an important factor accounting for hypertension.

Correlating all the risk factors for hypertension, we observed that the worst association was obesity and familial history of hypertension, which had a prevalence of $27 \%$, compared with other factors.

Anti hypertensive medications can cause side effects. However, the adverse drug reactions usually are not severe and are not experienced very often.

Finally, it is very important that physicians, pharmacists and nurses educate patients to understand their disease process which will help to improve compliance. It is suggested that programs for controlling systemic hypertension should be prioritized and better instruct the population about the reasons that could make compliance with the antihypertensive treatment difficult, jeopardizing the appropriate control of blood pressure and increasing cardiovascular morbidity and mortality.

\section{REFERENCES}

1. El-Shahat Yassin Ibrahim, M., 1999. Hypertension in UAE citizens-preliminary results of a prospective study. Saudi J. Kidney Dis. Transpl., 10: 376-381.

http://www.sjkdt.org/text.asp?1999/10/3/376/37247

2. Thomas Thom et al., 2006. Heart disease and stroke statistics 2006 update; a report from the American heart association statistics committee and stroke statistics subcommittee. Am. Heart Assoc. $\quad$ Circulat., 113: e85-e151. http://www.citeulike.org/user/gkiefer/article/941572

3. Wolz, M., J. Cutler and E.J. Roccella et al., 2000. Statement from the national high blood pressure education program: Prevalence of hypertension. Am. J. Hypertens., 13: 103-104. DOI: S08957061(99)00241-1

4. Joffres, M.R., P. Ghardirian, J.G. Fodor, A. Petrasovits, A. Chockalingam and P. Hamet, 1997. Awareness, treatment and control of hypertension in Canada. Am. J. Hypertens., 10: 1097-1102. http://www.ncbi.nlm.nih.gov/pubmed/9370379

5. Mallion, J.M. and D. Schmitt, 2001. Patient compliance in the treatment of arterial hypertension. J. Hypertens., 19: 2281-2282. http://direct.bl.uk/bld/PlaceOrder.do?UIN=105180 $100 \&$ ETOC $=$ RN\& from $=$ searchengine 
6. Gallup, G. and Jr. H.E. Cotugno, 1986. Preferences and practices of Americans and their physicians in antihypertensive therapy. Am. J. Med., 81: 20-24. http://www.ncbi.nlm.nih.gov/pubmed/2879454

7. Bloom, B.S., 1998. Continuation of initial antihypertensive therapy after one year of therapy. Clin. Ther., 20: 671-681. http://www.ncbi.nlm.nih.gov/pubmed/9737827

8. Dezii, C.M., 2000. A retrospective study of persistence with single-pill combination therapy vs. concurrent two-pill therapy in patients with hypertension. Manage. Care, 9: 2-6. http://www.ncbi.nlm.nih.gov/pubmed/11729417

9. Br. J. Clin. Pharmac, 1984. Patients compliance in hypertension-the importance of number of tablets. 17: 547-552.

http://www.pubmedcentral.nih.gov/articlerender.fc gi?artid=1463452

10. Martin Lamb, 2004. Improving patient compliance in clinical trials, PMPS-winter. http://www.almacgroup.com/papers/Papers/Improv ing_Patient_Compliance_in_CTS.pdf

11. Joel, M. Neutel and David H.G. Smith, 2003. Improving patient compliance: A major goal in the management of hypertension. J. Clin. Hypertens., 5: 127-132. DOI: $10.1111 / \mathrm{j} .1524-$ 6175.2003.00495.x

12. Jirage Reshma, 2009. Risks of high blood pressure medication. http://www.buzzle.com/articles/risksof-high-blood-pressure-medication.html

13. Oparil, S. and D.A. Calhoun, 1998. Managing the patient with hard-to-control hypertension. Am. Fam. Physician, 57: 1007-1014, 1019-1020. http://www.ncbi.nlm.nih.gov/pubmed/9518949

14. Suzanne, O. and D.A. Calhoun, 1998. Managing the patient with hard-to-control hypertension. Am. Acad. Family Physician., 57: 1007. http://www.aafp.org/afp/980301ap/oparil.html

15. Messerli, F.H., S. Oparil and Z. Feng, 2000. Comparison of efficacy and side effects of combination therapy of angiotensin-converting enzyme inhibitor (benazepril) with calcium antagonist (either nifedipine or amlodipine) versus high-dose calcium antagonist monotherapy for systemic hypertension. Am. J. Cardiol., 86: 1182-1187. http://www.ncbi.nlm.nih.gov/pubmed/11090788

16. Wolz, M., J. Cutler, E.J. Roccella et al., 2000. Statement from the national high blood pressure education program: Prevalence of hypertension. Am. J. Hypertens., 13: 103-104. DOI: S08957061(99)00241-1
17. Vokonas, J.M., W.B. Kannel and L.A. Cupples, 1988. Epidemiology and risk of hypertension in the elderly: The framingham study. J. Hypertens., 6: S3-S9. http://www.ncbi.nlm.nih.gov/pubmed/3216240

18. Statistical Research Group, 2002. Heart and stroke statistical update, American Heart Association. www.americanheart.org/downloadable/heart/HS_S tate_02.pdf

19. Freitas Olavo de Carvalho et al., 2001. Prevalence of hypertension in the urban population of catanduva, in the state of são paulo, Brazil. Arq. Bras. Cardiol., 77: 16-21. http://www.scielo.br/pdf/abc/v77n1/a02v77n1.pdf

20. National Institute of Health, 2000. Report of the national high blood pressure education program working group on high blood pressure in pregnancy. Am. J. Obstet. Gynecol., 183: S1-S22. http://www.ncbi.nlm.nih.gov/pubmed/10920346

21. Sadorf Marci R.N., 2009. Bayshore health and homemaker services. http://www.bayshorehomecare.com/Articles/Blood Pressure.htm

22. Radi, T. Lang and V. Lauwers-Cancès. 2005. Job constraints and arterial hypertension: Different effects in men and women: The IHPAF II case control study. Occupat. Environ. Med., 62: 711-717. DOI: 10.1136/oem.2004.012955

23. Kochar, M.S. and R.S. Bindra, 1996. The additive effects of smoking and hypertension. More reasons to help your patients kick the habit. Postgrad. Med., 100: 147-148, 151-154, 159-160. http://www.ncbi.nlm.nih.gov/pubmed/8917330

24. Nonpharmacological, 2001. Therapy of hypertension. Goodman and Gilman's, the pharmacological basis of therapeutics $11 \mathrm{e}$. http://www.accessmedicine.com/content.aspx?aID $=945063$

25. Friedrich Asen, 2008. Obesity is a risk to your health. http://www.redsofts.com/articles/read/102/32892/O besity_is_a_Risk_to_Your_Health.html

26. Frohlich, E.D. and J. Varagic, 2004. The role of sodium in hypertension is more complex than simply elevating arterial pressure. Nat. Clin. Pract. Cardiovasc. $\quad$ Med., 1 24-30. http://www.nature.com/ncpcardio/journal/v1/n1/pd f/ncpcardio0025.pdf

27. Metz, J.A. et al., 2000. A randomized trial of improved weight loss with a prepared meal plan in overweight and obese patients: Impact on cardiovascular risk reduction. Arch. Int. Med., 160: 2150-2158. http://archinte.amaassn.org/cgi/content/abstract/160/14/2150 
28. Marteau, J.B., M. Zaiou, G. Siest and S.V. Siest, 2005. Genetic determinants of blood pressure regulation. J. Hypertens., 23: 2127-2143. http://direct.bl.uk/bld/PlaceOrder.do?UIN=178165 $614 \&$ ETOC $=$ RN\& from $=$ searchengine

29. Chobanian, A.V. et al., 2003. The seventh report of the joint national committee on prevention, detection, evaluation and treatment of high blood pressure. J. Am. Med. Assoc., 289: 2560-2571. http://jama.ama-assn.org/cgi/content/abstract/289/19/2560

30. Lees, K.R., J.L. Reid, M.G. Scott, J. Hosie, D. Herpin and J.P. Santoni, 1989. Captopril versus perindopril: A double blind study in essential hypertension. J. Hum. Hypertens., 31: 17-22. http://www.ncbi.nlm.nih.gov/pubmed/2657055

31. Novartis Pharmaceuticals Corp, 2007. Diversity inc recognizes novartis as one of the top 50 companies for diversity. http://www.pharma.us.novartis.com/index.jsp?chec ked $=$ y\&usertrack.filter_applied $=$ true $\&$ NovaId $=335$ 0119544727574519
32. GlaxoSmithKline, 2008. Highlights of prescribing information, these highlights do not include all the information needed to use KINRIX safely and effectively. See full prescribing information for KINRIX.

http://www.fda.gov/cber/label/kinrixLB.pdf

33. Bristol-Myers Squibb, 2003. MONOPRIL (fosinopril sodium tablets). http://www.fda.gov/medWatch/SAFETY/2003/03 Oct_PI/Monopril_PI.pdf

34. Micromedex, 2008. Atenolol side effects. http://www.drugs.com/sfx/atenolol-side-effects.html 